\title{
LA "S. A. DE EXTRACTOS TÁNICOS" DE BARCELONA: \\ UN PROYECTO EMPRESARIAL A TRAVÉS DEL QUEBRACHO \\ PARAGUAYO
}

\author{
Gabriela Dalla-Corte CABAllero ${ }^{1}$ \\ TEIAA-UNIVERSITAT DE BARCELONA
}

\begin{abstract}
RESUMEN: Se analiza la "S. A. de Extractos Tánicos", fundada en el Pueblo Nuevo de Barcelona en el año 1909 por los hermanos Pedro Pablo, Fernando y Carlos de Corral y Tomé. El matrimonio de Pedro Pablo de Corral y Tomé con Clara Margarita Casado Sastre nos permite reconstruir la vinculación familiar y empresarial entre la empresa barcelonesa dedicada a la importación de la "quiebra hacha" paraguaya, y la "S. A. Carlos Casado Limitada, Compañía de Tierras", la fábrica del quebracho colorado establecida en el Gran Chaco latinoamericano.
\end{abstract}

PALABRAS CLAVE: Paraguay, Quebracho, Barcelona, Extractos Tánicos, Curtiembre.

\section{THE "S. A. OF TANNIN EXTRACTS" OF BARCELONA: BUSINESS PROJECT THROUGH THE PARAGUAYAN QUEBRACHO}

\begin{abstract}
We analyze the "S. A. Tannin Extracts", founded in Pueblo Nuevo of Barcelona in 1909 by brothers Pedro Pablo, Fernando and Carlos de Corral y Tomé. The marriage of Pedro Pablo de Corral with Clara Margarita Casado Sastre allows us to reconstruct the family and business links between the Barcelona Company dedicated to the import of the "quiebra hacha" of Paraguay, and the "S. A. Carlos Casado Limited Land Company", the quebracho factory established in the Gran Chaco of Latin America.
\end{abstract}

KEY WORDS: Paraguay, Quebracho, Barcelona, Tannin Extracts, Tannery.

Recibido: 17-06-2013/Aceptado: 14-10-2013

\footnotetext{
1 Este trabajo se inscribe en el proyecto del Ministerio de Economía y Competitividad HAR2012-34095, desarrollado en el seno del TEIAA, Taller de Estudios e Investigaciones Andino-Amazónicos (2009SGR1400), grupo de investigación consolidado por el Comissionat per a Universitats i Recerca del DIUE de la Generalitat de Catalunya. Agradezco los comentarios y sugerencias de los/las evaluadores/as de este artículo.
} 
Llegada a su fin la terrible Guerra de la Triple Alianza contra el Paraguay (1865-1870), la fabricación del extracto tánico del árbol de quebracho colorado fue acompañada por el monopolio del territorio chaqueño en manos de un reducido número de latifundistas extranjeros. Uno de los personajes más vinculados a dicho monopolio territorial fue el español Carlos Casado del Alisal, quien en los años 1886 y 1889 adquirió unas 3.000 leguas cuadradas en las que estableció su "Compañía de Tierras Hispano-Paraguaya Limitada", dedicada esta última a la industrialización del quebracho chaqueño. En virtud del desarrollo de esta gran fábrica, la sociedad paraguaya le adjudicó al empresario Carlos Casado el calificativo de "Barón del Chaco".

Fallecido en 1899, una década después sus descendientes abandonaron el calificativo de "hispano-paraguaya", y registraron esta empresa en la ciudad de Buenos Aires, es decir, en la capital argentina. También decidieron rebautizarla con el nombre de "S. A. Carlos Casado Limitada, Compañía de Tierras", hoy vigente, con la intención de internacionalizar su producción y su comercialización ${ }^{2}$. Esta empresa fundada por el palentino Carlos Casado del Alisal en el año 1889, y convertida por sus descendientes en sociedad anónima en el año 1909, fue utilizada desde entonces para garantizar la exportación de rollizos y extractos tánicos hacia Europa y hacia los Estados Unidos. La infraestructura de la fábrica permitió tratar in situ la madera con el consiguiente ahorro de costes y de fletes, al exportar el extracto elaborado o semielaborado en sacos de yute de 50 $\mathrm{kg}$ de peso, una exportación que tuvo como gran destino la zona del Pueblo Nuevo de la ciudad de Barcelona.

Fue en la ciudad condal donde el yerno de Casado, Pedro Pablo de Corral y Tomé, más conocido como $3^{\circ}$ vizconde de Oña, fundó a inicios del siglo XX la "Fábrica de Extractos Curtientes" en el Pueblo Nuevo de la ciudad de Barcelona. La empresa se dedicó desde sus inicios a la fabricación de extracto tánico derivado de la madera del quebracho. En el Pueblo Nuevo barcelonés adquirió tres manzanas entre las calles Perelló, Carril, Vidal y Valenciano, así como el Paseo de Calvell, mientras el despacho fue establecido en la calle Lauria número 9, es decir, en pleno centro de la ciudad condal.

Desde entonces, la unidad entre ambos proyectos empresariales garantizó la importación indiscriminada del quebracho colorado paraguayo por el Puerto de Barcelona. En 1916, la empresa pasó a llamarse “S. A. de Extractos Tánicos”, hoy también vigente. El momento en que se produjo esta transformación no fue otro que el estallido de la Primera Guerra Mundial, el cual explica el propio desarrollo industrial del extracto tánico dedicado

2 DALLA-CORTE CABALLERO, Gabriela: Lealtades firmes. Redes de sociabilidady empresas en la Carlos Casado $S$. A. entre Argentina y el Chaco paraguayo, 1860-1940, Madrid, CSIC, 2009. 
a la curtición: este producto natural -también llamado "oro rojo" en el Gran Chaco- fue utilizado para el curtido de las suelas de zapatos y botas de los ejércitos europeos y estadounidenses.

Este trabajo reconstruye la vinculación empresarial y familiar de ambas fábricas dedicadas a la producción de tanino natural para el curtido de las suelas de zapatos y botas de los ejércitos en guerra. Hablamos de la compañía organizada por Carlos Casado, y de la ejecutada por su yerno Pedro Pablo de Corral y Tomé junto a sus hermanos Fernando y Carlos. El objetivo es analizar el crecimiento de la producción y de la comercialización del extracto tánico del quebracho colorado desde finales del siglo XIX.

El primer apartado describe el desempeño de Pedro Pablo de Corral y Tomé al contraer matrimonio con una de las hijas del empresario palentino Carlos Casado, precisamente la rosarina Clara Margarita Casado Sastre, y al diseñar la creación de la "Fábrica de Extractos Curtientes" en la ciudad de Barcelona. El segundo apartado analiza el proyecto implementado por los hermanos de Corral y Tomé al transformar esa empresa y convertirla en "S. A. de Extractos Tánicos". En el tercero se describe la participación de la empresa en la Exposición Internacional organizada en la ciudad de Barcelona en el año 1929, así como el sentido otorgado por sus responsables a los seguros internacionales en el periodo de entreguerras. Desde entonces, la empresa sufrió una gran declinación productiva de la mano de la crisis económica internacional iniciada en ese año de 1929; de la Guerra del Chaco entre Paraguay y Bolivia (1932-1935); de la Guerra Civil española (1936-1939); y de la Segunda Guerra Mundial (1939-1945). Por ello, en la conclusión de este artículo se plantea la decadencia del quebracho a partir de 1940, y se señalan las consecuencias producidas por la imposición internacional de los tánicos sintéticos para el curtido.

\section{LOS INICIOS DE LA “FÁBRICA DE EXTRACTOS CURTIENTES” DE BARCELONA}

Como mencionamos en la introducción de este artículo, en el año 1909 la "Compañía de Tierras Hispano-Paraguaya Limitada" se convirtió en sociedad anónima. Paralelamente, una asamblea general extraordinaria de accionistas, convocada a través del Boletín Oficial argentino, decidió transformar el nombre de la empresa familiar. Pedro Casado Sastre, por entonces presidente de la compañía, organizó la reunión en las oficinas de la calle San 
Martín 158 de Buenos Aires. La reunión comenzó con el nombramiento de Antonio L. de Tejada y de Carlos E. Sastre como veedores.

Ahora bien: Pedro Casado Sastre cedió la palabra a su cuñado, Pedro Pablo de Corral y Tomé, el marido de Clara Margarita Casado Sastre, quien, cumpliendo con su función de secretario-tesorero, sugirió abandonar los términos "hispano" y "paraguayo", y adoptar una nueva designación como "justo tributo a la memoria del creador...aquel admirable hombre de negocios". También sugirió la necesidad de que la empresa no fuese asociada a ninguna "nacionalidad extranjera". En sus palabras, era hora de crear empresas que llevaran un nombre significativo, pero ya no las nacionalidades elegidas por sus creadores, en este caso concreto las de Paraguay y España:

El nombre de La Hispano-Paraguaya tuvo su oportunidad cuando se trataba exclusivamente de negocios relacionados con la fábrica de extracto de quebracho que era conocido de antiguo con ese título, pero que debiendo extenderse las operaciones de la Compañía a un círculo más amplio de iniciativas en gran parte radicadas en la República Argentina, resultaría notoriamente impropio que capitales, intereses y administración nacionales hubiesen de ostentar como distintivo un nombre doblemente expresivo de nacionalidad extranjera, y que a la vez no abarca en su significado el objeto de empresa ${ }^{3}$.

Desde el año 1909, la empresa se dio a conocer con el nombre de "S. A. Carlos Casado Limitada, Compañía de Tierras"4. El presidente argentino José Figueroa Alcorta aprobó sus estatutos que fijaron una duración máxima de noventa años. Los mencionados estatutos fueron aprobados por la División de Justicia de Buenos Aires el 7 de octubre de 1909, y registrados en el 21 de octubre de ese año. El 29 de noviembre fueron inscriptos en el Registro Público de Comercio de la capital argentina ${ }^{5}$.

\footnotetext{
${ }^{3}$ Resolución del gobierno paraguayo del 10 de abril de 1911 aprobando la modificación de los estatutos de la S. A. Carlos Casado Limitada Compañia de Tierras, propiedad de Carlos Casado y establecida en la República Argentina, Asunción del Paraguay, Registro Oficial de la República del Paraguay del año 1911, Talleres Gráficos del Estado, 1920, p. 73.

${ }^{4}$ Museo Archivo Histórico Municipal “Don Santos Tosticarelli” (MAHM), Testimonio de dación en pago otorgado por el albacea de la sucesión de Carlos Casado (Carlos Mateo Casado Sastre) a favor de Ramona Sastre Aramburu de Casado, Escribano público actuante Arturo Covernton (calle Santa Fe, 858, ciudad de Rosario), Créditos - Quintas y fincas Rosario, Casilda, 1906. Incluye los terrenos adjudicados a Ramona Sastre por la escritura de hijuela en Argentina y en la República del Paraguay.

5 MAHM, Casilda, Provincia de Santa Fe, República Argentina, Documento Suelto: Estatutos de la "S. A. Carlos Casado Limitada, Compañía de Tierras" del año 1909-1910, en sustitución de la "Compañía de Tierras La Hispano-Paraguaya Limitada", en Poder General otorgado por el doctor Pedro Casado y por Manuel Benigno Goñi Coll, presidente y secretario, respectivamente, del directorio de la empresa, a favor de Antonio V. Zabalza, ante los escribanos Horacio Turio y Miguel B. Spinosa, Buenos Aires, 1913.
} 
Gracias a esta transformación, los herederos de Carlos Casado del Alisal introdujeron la raza bovina "Hereford" para volcarse a la ganadería y al curtido de pieles. Hasta entonces se había constituido por un total de 136.000 acciones diferenciadas en ordinarias y preferidas. En aquel año se unificaron las acciones en ordinarias, con la finalidad de asimilarlas a las transacciones bursátiles permitiendo, al mismo tiempo, la entrada de capital. Los accionistas acordaron que el objetivo de la empresa era "dedicarse a la explotación de bosques y campos en general y a la compra venta de bienes, muebles o inmuebles, tanto en el territorio de la República Argentina como en el extranjero", haciendo alusión directa al Paraguay y a España, y concluyeron que "las circunstancias actuales y el ambiente de opinión de un número considerable de accionistas han inducido al directorio a determinar la presente como época oportuna para llevar a cabo este objeto”. Se decidió entonces ampliar el capital social, así como su depósito en el Banco de la Nación Argentina, en el Banco Español del Río de la Plata, en el Banco Francés del Río de la Plata, en el Banco de Londres y Río de la Plata, así como en el Banco Británico de la América del Sur, entre otros tantos bancos no paraguayos.

Como vemos, esta nueva empresa consiguió diversificar sus actividades e internacionalizar la fábrica dedicada al tanino del quebracho. El gobierno argentino aprobó estos cambios el 18 de julio de 1910, y el gobierno paraguayo hizo lo propio el 10 de abril de 1911. Los nuevos estatutos fueron protocolizados por el Juzgado Comercial de Asunción del Paraguay el 27 de octubre de 1910. El Registro Público de Comercio asunceño inscribió a la sociedad anónima dos días después ${ }^{7}$. El 4 de noviembre de 1912 tuvo lugar una asamblea general ordinaria convocada en el Boletín Oficial y en La Prensa de Buenos Aires. Participó en este acto el Inspector general de justicia, Francisco Ramos, y presidieron la asamblea Pedro Casado Sastre y su cuñado Manuel Benigno Goñi Coll. Por esas fechas, la viuda Ramona Sastre Aramburu poseía 70.102 acciones de un total de 292.502, con lo cual conservaba el 24,92 \% del total del capital social, asegurándose, al mismo tiempo, un voto preferente en el seno de las reuniones anuales y semestrales.

\footnotetext{
${ }^{6}$ MAHM, copia de los prenotados de la partición practicada en los autos sucesorios del año 1900. Escritura de dación en pago otorgada por el albacea de la sucesión de Carlos Casado del Alisal (Carlos Mateo Casado Sastre) a favor de Ramona Sastre Aramburu, escribano Pantaleón Egúrvide, secretaría 22 del Juzgado de Segunda Nominación, Rosario, 1906.

7 DALLA-CORTE CABALLERO, Gabriela: "Extranjeros en el Paraguay de entreguerras. Actores y disputas en el proyecto nacional en el Chaco Boreal", en E. Sánchez (coord.): Actores locales de la nación en América Latina. Estudios estratégicos, Puebla, Benemérita Universidad Autónoma de Puebla, El Colegio de Tlaxcala, A. C., 2011, pp. 201-236.
} 
La mencionada distribución empresarial reforzó el papel ejercido por Clara Margarita Casado Sastre, la esposa de Pedro Pablo de Corral y Tomé. En diciembre de 1896, Pedro Pablo fue incorporado al Regimiento de León $n^{\circ} 38$. Nacido en Madrid, y nombrado como $3^{\circ}$ vizconde de Oña, asumió la profesión diplomática y se convirtió en agregado militar en la Embajada de España en la República Argentina. Por ello decidió embarcarse en Vigo para llegar a Buenos Aires en el barco "Capitán Arcona”.

En la capital argentina, Pedro Pablo representó inicialmente a las industrias vizcaínas dedicadas al bisulfito de sosa ${ }^{9}$. A inicios del siglo XX contrajo matrimonio con la rosarina Clara Margarita, la hija de Carlos Casado y de Ramona Sastre. Desde la "casamatriz" de la empresa, es decir, desde Puerto Casado, Pedro Pablo se encargó de hacer llegar al Puerto de Barcelona una fabulosa cantidad de rollizos de madera del quebracho. En 1909 fundó con sus hermanos la fábrica barcelonesa dedicada a los extractos tánicos ${ }^{10}, \mathrm{y}$ dejó en las manos de Carlos y de Fernando la construcción de una nave en el Pueblo Nuevo para garantizar el negocio de importación de maderas de quebracho y de extractos vegetales con tanino para la curtición ${ }^{11}$.

Conviene ahora explicar la distinción entre extracto de quebracho elaborado o semielaborado, o lo que es lo mismo (y por emplear términos químicos del extracto de quebracho), soluble o insoluble en agua fría. Las características del "oro rojo”, así llamado popularmente el árbol de quebracho, son tan especiales, que de la fabricación de su extracto, una vez molturada y efectuada su extracción, se obtiene un producto seco. Si bien supone un extraordinario avance, el mencionado producto seco tiene dos características que, históricamente, no se podían solucionar en origen en las fábricas de Carlos Casado, razón por la cual era necesaria la tecnología aportada por la "S. A. de Extractos Tánicos" en el Pueblo Nuevo barcelonés. La primera característica señala que el extracto resultante, al ser insoluble en agua fría, no permitía su utilización directa por los curtidores. La

\footnotetext{
${ }^{8}$ Diario Oficial del Ministerio de la Guerra, Año IX, No 292, domingo 27 de diciembre de 1896, Tomo IV, p. 1640.

9 [DEULOFEU], La Vanguardia, martes 8 de setiembre de 1903, p. 2. RODRÍGUEZ NOZAL, Raúl y GONZÁLEZ BUENO, Antonio: Entre el Arte y la Técnica. Los Orígenes de la Fabricación Industrial del medicamento, Madrid, Ministerio de Educación y Ciencia, CSIC, Servicios Integrales de Edición Távara, S.L., 2005, p. 190. ${ }^{10}$ Gracias a los datos ofrecidos por La Vanguardia, Barcelona, jueves 6 de abril de 1893, p. 2, en abril de 1893 , la Comisión Provincial trasladó a la Sección de Quintas del distrito de la Universidad una Real Orden comunicada por el Gobernador Civil de la provincia, en la que se concedió el indulto al mozo Carlos de Corral y Tomé, prófugo del reemplazo de 1889, alistado en la referida Sección, quedando sujeto a las prescripciones de los artículos $1^{\circ}, 4^{\circ}$ y $5^{\circ}$ de la Ley del 22 de julio de 1892 . Poco después se integró como "tirador" al Tiro Nacional de Barcelona, en el cual participaban aproximadamente más de cuatro mil asociados. Véase también, La Vanguardia, Barcelona, 4 de mayo de 1920, p. 2; "Tiro Nacional", La Vanguardia, Barcelona, sábado 9 de diciembre de 1922, p. 8.

11 Convertido en fabricante de curtidos, es importante señalar que, en el año 1923, Pedro Pablo de Corral y Tomé recibió la cruz blanca de segunda clase del mérito militar en calidad de Comandante de Infantería; La Vanguardia, Barcelona, miércoles 21 de febrero de 1923, p. 17; A. B. C., Madrid, 21 de febrero de 1923, p. 16.
} 
segunda supone que el nombre dado al quebracho, el de "oro rojo", se vincula con ese color, y en Europa el quebracho debía competir con el extracto de mimosa y de castaño. Ese vegetal chaqueño confiere a la piel un color claro que es exigido por el mercado desde finales del siglo XIX para el proceso de curtición. Estas dos problemáticas no encontraron solución en el espacio chaqueño, pero permitieron a la "S. A. de Extractos Tánicos" la implementación de este novedoso sistema productivo, solubilizando y decolorando el extracto que se importaba en sacos de $50 \mathrm{~kg}$, como mencionamos en la introducción de este artículo.

La genealogía de Pedro Pablo de Corral y Tomé nos permite reconstruir precisamente su vinculación con la familia de Carlos Casado del Alisal y Ramona Sastre Aramburu. Pedro Pablo era el nieto de Tomás Eustaquio de Corral y Oña, el Médico de Cámara de la Reina de España. Precisamente Isabel II lo nombró $1^{\circ}$ marqués de San Gregorio y también $1^{\circ}$ vizconde de Oña. Nacido en 1807 en Villa de Leiva, La Rioja, y fallecido en 1882 en Madrid, Tomás Eustaquio de Corral y Oña contrajo matrimonio con Eugenia Usera y Alarcón, con quien tuvieron los siguientes hijos e hijas, y de apellido de Corral y Usera: Eugenio María, Luisa, Marcelo, Lorenzo, Isabel, María de la Purificación, Consuelo y Fernando Luis.

Fernando Luis de Corral y Usera nació en Madrid el 19 de enero de 1846, y fue nombrado $2^{\circ}$ marqués de San Gregorio, y también $2^{\circ}$ vizconde de Oña. Contrajo matrimonio con María de la Paz Tomé y Martínez, y tuvieron los siguientes hijos de apellido de Corral y Tomé: Alfonso, Carlos, Tomás, Pedro Pablo y Fernando. De ellos, Tomás asumió como $3^{\circ}$ marqués de San Gregorio. Su hermano Pedro Pablo, el personaje que analizamos aquí, fue nombrado $3^{\circ}$ vizconde de Oña. ${ }^{12}$ En la República Argentina, Pedro Pablo y su esposa rosarina Clara Margarita Casado Sastre tuvieron cinco hijas y dos hijos. Para acabar este apartado, reproducimos la genealogía de la familia de Corral y Casado Sastre que demuestra la conexión de las dos empresas dedicadas a la internacionalización de los productos naturales paraguayos.

${ }^{12}$ HERRERA VEGAS, D. J., y JÁUREGUI RUEDA, Carlos: Familias Argentinas, Buenos Aires, Ediciones Callao 1823, 2006. 


\begin{tabular}{|c|c|c|c|c|}
\hline \multirow{2}{*}{\multicolumn{5}{|c|}{$\begin{array}{l}\text { Genealogía de Pedro } \\
\text { María Margarita (1905-) }\end{array}$}} \\
\hline & & & & \\
\hline \multirow{11}{*}{$\begin{array}{l}\text { Elizabeth } \\
\text { (Isabel) Isidora } \\
\text { de Corral y } \\
\text { Casado Sastre } \\
(1906---)\end{array}$} & \multicolumn{4}{|c|}{ + Horacio Luis Zorraquín y Lynch } \\
\hline & \multirow[t]{10}{*}{ Hijos/as } & \multirow{7}{*}{$\begin{array}{l}\text { Isabel Zorraquín } \\
\text { y de Corral } \\
(1940)\end{array}$} & \multicolumn{2}{|c|}{ + Vicente Sartorius y Cabeza de Vaca, $4^{\circ}$ marqués de Mariño } \\
\hline & & & \multirow[t]{5}{*}{ Hijos } & Isabel Sartorius y Zorraquín (1965, Madrid) + Javier \\
\hline & & & & Fitz-James Stuart de Soto. \\
\hline & & & & $\begin{array}{l}\text { Hija: Mencía Fitz-James Stuart Sartorius, } 25 \text { de julio } \\
\text { de } 1997\end{array}$ \\
\hline & & & & $\begin{array}{l}\text { Cecilia Sartorius y Zorraquín (1967) + Federico } \\
\text { Green. } \\
\text { Hijo: Federico Green }\end{array}$ \\
\hline & & & & $\begin{array}{l}\text { Luis José Sartorius y Zorraquín (1970) + Bárbara } \\
\text { Pérez Manzarbeitia. } \\
\text { Hijos/as: Vicente Sartorius Pérez (2011), Isabel } \\
\text { Sartorius Pérez (2012) }\end{array}$ \\
\hline & & & \multicolumn{2}{|c|}{ + Manuel Ulloa y Elías (segundas nupcias) } \\
\hline & & \multirow{2}{*}{$\begin{array}{l}\text { Diego Zorraquín } \\
\text { y de Corral }\end{array}$} & \multicolumn{2}{|c|}{ + Maria Luisa Bosch Peralta Ramos } \\
\hline & & & \multicolumn{2}{|c|}{ + Claudia Cassinelli (segundas nupcias) } \\
\hline & & $\begin{array}{l}\text { Álvaro } \\
\text { Zorraquín y de } \\
\text { Corral (1944) }\end{array}$ & \multicolumn{2}{|c|}{+ Alina Negrotto Pico } \\
\hline \multirow[t]{8}{*}{$\begin{array}{l}\text { Helena Justa de } \\
\text { Corral y Casado } \\
\text { Sastre (1911- } \\
\text { 2007) }\end{array}$} & \multicolumn{4}{|c|}{$\begin{array}{l}\text { + Alejandro Pidal y Toro de Guzmán, } 2^{\circ} \text { marqués de Valderrey (1909---), nobiliario título creado } \\
\text { por Alfonso XIII en agosto de } 1914 \text { para su padre Manuel Pidal y Bernaldo de Quirós, por } \\
\text { entonces diputado en las Cortes españolas y casado con María de los Dolores Toro y Sánchez- } \\
\text { Arjona }\end{array}$} \\
\hline & \multirow[t]{7}{*}{ Hijos/as } & Alejandro María & \multicolumn{2}{|c|}{ + Marta Ochoa } \\
\hline & & $\begin{array}{l}\text { Pidal de Corral, } \\
3^{\text {o marqués de }} \\
\text { Valderrey (1909- } \\
- \text { ) }\end{array}$ & Hijos/as & $\begin{array}{l}\text { María Pidal Ochoa, Dolores Pidal Ochoa, Alejandro } \\
\text { Pidal Ochoa, Rodrigo Pidal Ochoa (+ Margarita } \\
\text { Fernández Sasso, 1969), Francisco Pidal Ochoa (+ } \\
\text { Rosemarie Martin Durrieu), Ignacio Pidal Ochoa (+ } \\
\text { Margarita Peralta Fariña) }\end{array}$ \\
\hline & & $\begin{array}{l}\text { Helena Pidal de } \\
\text { Corral }\end{array}$ & \multicolumn{2}{|c|}{ + Gonzalo Ponce de León } \\
\hline & & $\begin{array}{l}\text { Inés Pidal de } \\
\text { Corral }\end{array}$ & \multicolumn{2}{|l|}{$\mathrm{s} / \mathrm{d}$} \\
\hline & & $\begin{array}{l}\text { Juan Pidal de } \\
\text { Corral }\end{array}$ & \multicolumn{2}{|l|}{$\mathrm{s} / \mathrm{d}$} \\
\hline & & Santiago Pidal de & \multicolumn{2}{|c|}{ + Cora Torres Duggan Zemborain } \\
\hline & & Corral & Hijos/as & $\begin{array}{l}\text { Santiago Pidal Torre Dugan, Susana Pidal Torre } \\
\text { Dugan, Milagros Pidal Torre Dugan }\end{array}$ \\
\hline
\end{tabular}




\begin{tabular}{|c|c|c|c|c|}
\hline \multirow{11}{*}{$\begin{array}{l}\text { Isidro de Corral } \\
\text { y Casado Sastre } \\
\text { (1913, Buenos } \\
\text { Aires- 2001) }\end{array}$} & \multicolumn{4}{|c|}{$\begin{array}{l}\text { + Inés María Victorica Roca Chevallier (1915, Buenos Aires- 1994, Buenos Aires) } \\
\text { + María Elisa Walsh y Cruz (segundas nupcias) }\end{array}$} \\
\hline & \multirow[t]{10}{*}{ Hijos/as } & \multirow{2}{*}{$\begin{array}{lr}\text { Margarita } & \text { Inés } \\
\text { de } & \text { Corral } \\
\text { Victorica } & \end{array}$} & \multicolumn{2}{|c|}{ + Enrique Braun Estrugamou } \\
\hline & & & Hijos/as & $\begin{array}{l}\text { Enrique Braun Corral, Marcelo Braun Corral, } \\
\text { Máximo Braun Corral, María Inés Braun Corral, } \\
\text { Angélica Braun Corral }\end{array}$ \\
\hline & & \multirow[t]{2}{*}{$\begin{array}{l}\text { Justo José de } \\
\text { Corral Victorica }\end{array}$} & \multicolumn{2}{|c|}{$\begin{array}{l}\text { + Silvina Hayes Martínez Crovetto } \\
\text { + Bernardita Prieto Vial. }\end{array}$} \\
\hline & & & Hija & Bernardita Inés de Corral Prieto \\
\hline & & \multirow[t]{2}{*}{$\begin{array}{l}\text { Carlos Julio de } \\
\text { Corral Victorica }\end{array}$} & \multicolumn{2}{|c|}{$\begin{array}{l}\text { + María Cristina Cassinelli } \\
\text { + Susana Rodríguez Martins }\end{array}$} \\
\hline & & & Hijos/as & $\begin{array}{l}\text { Tomás de Corral Rodríguez Martins, Gonzalo de } \\
\text { Corral Rodríguez Martins, María Julia de Corral } \\
\text { Rodríguez Martins. }\end{array}$ \\
\hline & & \multicolumn{3}{|c|}{ Elisa María de Corral Walsh } \\
\hline & & \multicolumn{3}{|c|}{ María Sol de Corral Walsh } \\
\hline & & \multicolumn{3}{|c|}{ Isabel de Corral Walsh } \\
\hline & & \multicolumn{3}{|c|}{ Marina de Corral Walsh } \\
\hline \multirow{13}{*}{$\begin{array}{l}\text { Angélica de } \\
\text { Corral y Casado } \\
\text { Sastre (Buenos } \\
\text { Aires, 1914---) }\end{array}$} & \multicolumn{4}{|c|}{$\begin{array}{l}\text { + Horacio Elías José Bernardino Nazar y Méndes Gonçalves (1912, Buenos Aires-1992, Buenos } \\
\text { Aires) }\end{array}$} \\
\hline & \multirow[t]{12}{*}{ Hijos/as } & \multirow{2}{*}{$\begin{array}{l}\text { Horacio Pío } \\
\text { Nazar de Corral } \\
(1938, \quad \text { Buenos } \\
\text { Aires---) }\end{array}$} & \multicolumn{2}{|c|}{ + Magdalena Pereyra Iraola Peña } \\
\hline & & & Hijos/as & $\begin{array}{l}\text { Magdalena Nazar Pereyra Iraola, Pablo Nazar Pereyra } \\
\text { Iraola, Sofía Nazar Pereyra Iraola, Marcos Nazar } \\
\text { Pereyra Iraola, Milagros Nazar Pereyra Iraola, Tomás } \\
\text { Nazar Pereyra Iraola }\end{array}$ \\
\hline & & \multirow{2}{*}{$\begin{array}{l}\text { Mercedes Nazar } \\
\text { de Corral }\end{array}$} & \multicolumn{2}{|c|}{ + Mario Juan Copello } \\
\hline & & & Hijo & Nicolás Santiago Copello Nazar \\
\hline & & \multirow{2}{*}{$\begin{array}{l}\text { Angélica Nazar } \\
\text { de Corral }\end{array}$} & \multicolumn{2}{|c|}{ + Miguel Ramón Grondona y Pereyra Iraola } \\
\hline & & & Hijos/as & $\begin{array}{l}\text { Angélica Grondona Nazar, Miguel Grondona Nazar, } \\
\text { Sebastián Grondona Nazar, Agustín Grondona Nazar }\end{array}$ \\
\hline & & \multirow{2}{*}{$\begin{array}{l}\text { Stella Nazar de } \\
\text { Corral }\end{array}$} & \multicolumn{2}{|c|}{ + Juan Peralta Ramos Simbonnet } \\
\hline & & & Hijos/as & $\begin{array}{l}\text { Alejandra Peralta Ramos Nazar, Angélica Peralta } \\
\text { Ramos Nazar }\end{array}$ \\
\hline & & \multirow{2}{*}{$\begin{array}{l}\text { Pedro Pablo } \\
\text { Nazar de Corral }\end{array}$} & \multicolumn{2}{|c|}{ + Hebe Larroudé Mazza } \\
\hline & & & Hijos/as & $\begin{array}{l}\text { Carmen Nazar Larroudé, Juan Pablo Nazar Larroudé, } \\
\text { Dolores Nazar Larroudé, Fátima Nazar Larroudé }\end{array}$ \\
\hline & & \multirow{2}{*}{$\begin{array}{l}\text { Carlos Nazar de } \\
\text { Corral }\end{array}$} & \multicolumn{2}{|c|}{ + Nora Monti } \\
\hline & & & Hijos/as & $\begin{array}{l}\text { Marina Nazar Monti, Camila Nazar Monti, Theo } \\
\text { Nazar Monti }\end{array}$ \\
\hline
\end{tabular}




\begin{tabular}{|c|c|c|c|c|}
\hline \multirow{5}{*}{$\begin{array}{lr}\text { Fernando } & \text { Luis } \\
\text { Alberto } & \text { de } \\
\text { Corral y } & \text { Casado } \\
\text { Sastre } & \text { (1916, } \\
\text { Buenos } & \text { Aires- } \\
1984) & \end{array}$} & \multicolumn{4}{|c|}{ + Beatriz Marta Castells Aznárez } \\
\hline & \multirow[t]{5}{*}{ Hijos/as } & \multirow{2}{*}{$\begin{array}{l}\text { María de Corral } \\
\text { Castells }\end{array}$} & \multicolumn{2}{|c|}{ + Mario Padilla } \\
\hline & & & Hijos/as & $\begin{array}{l}\text { Juan Manuel Padilla de Corral, Luis Padilla de Corral, } \\
\text { Dolores Padilla de Corral }\end{array}$ \\
\hline & & \multicolumn{3}{|c|}{ Fernando de Corral Castells } \\
\hline & & \multicolumn{3}{|c|}{ Raúl de Corral Castells } \\
\hline & & \multicolumn{3}{|c|}{ Teresa de Corral Castells } \\
\hline \multirow{6}{*}{$\begin{array}{l}\text { Estela Ramona } \\
\text { de Corral y } \\
\text { Casado Sastre } \\
\text { (1919, Buenos } \\
\text { Aires---) }\end{array}$} & \multicolumn{4}{|c|}{ + Jorge Berro Madero Seeber (hijo de Carlos Berro Madero y Graciela Seeber Agrelo) } \\
\hline & \multirow[t]{5}{*}{ Hijos/as } & Jorge & \multirow{2}{*}{\multicolumn{2}{|c|}{ + Elena María Basombrío Gigena }} \\
\hline & & $\begin{array}{l}\text { Madero de } \\
\text { Corral }\end{array}$ & & \\
\hline & & $\begin{array}{l}\text { Pedro Pablo } \\
\text { Berro Madero de } \\
\text { Corral }\end{array}$ & \multicolumn{2}{|c|}{ + Clara Steverlynck Berisso } \\
\hline & & $\begin{array}{lr}\text { María } & \text { Berro } \\
\text { Madero } & \text { de } \\
\text { Corral } & \\
\end{array}$ & \multicolumn{2}{|c|}{ + Pedro Miquens Casabal } \\
\hline & & $\begin{array}{lr}\text { Margarita } & \text { Berro } \\
\text { Madero } & \text { de } \\
\text { Corral } & \\
\end{array}$ & \multicolumn{2}{|c|}{ + Pablo Carlos María Hary Avendaño } \\
\hline
\end{tabular}

\section{LA “S. A. DE EXTRACTOS TÁNICOS" DEL PUEBLO NUEVO DE BARCELONA}

Fernando y Carlos de Corral y Tomé, los dos hermanos de Pedro Pablo establecidos en la ciudad condal, también fundaron e inauguraron en pleno año 1909 la revista barcelonesa llamada El Arte de Curtir. En el año 1929, esta publicación adoptó el nombre La Piel y sus Industrias, el arte de curtir.

El primer número de esta publicación catalana salió a la luz en el preciso momento en que abrió sus puertas la "Fábrica de Extractos Curtientes". La cifra de producción de esta empresa osciló los cinco millones de kilos anuales que servían para el curtido de la piel y sus derivados. Para el buen orden de sus cuantiosas operaciones, la fábrica de los tres hermanos Corral y Tomé estableció depósitos en Igualada, Valencia, Palma de Mallorca, Málaga, Noya, Santander y Salamanca, y organizó una agencia en Oporto, la cual extendió a Portugal el radio de acción de esta poderosa empresa convertida en modelo para todas las fábricas de su clase. Fallecido Fernando de Corral y Tomé en 
1911, su hermano Carlos asumió la presidencia de la razón social y se incorporó como tesorero en la Cámara Argentina de Comercio en España.

Dedicados desde su inicio a la importación del quebracho colorado, la vinculación con los Casado-Sastre les permitió a los hermanos de Corral y Tomé volcarse al negocio y a la fabricación derivada del extracto tánico en Barcelona. Carlos había investigado sobre las ventajas y los inconvenientes de la curtición por medio de los sistemas rápidos o lentos, con aplicación directa de los extractos del tanino de quebracho. Desde 1916 utilizó la "S. A. de Extractos Tánicos" para la recepción, fabricación y venta de rollizos y extractos para curtir, en especial los provenientes del quebracho, de la encina, de la mimosa, del castaño y del zumaque.

Carlos de Corral y Tomé actuó en representación de su hermano Pedro Pablo, junto a Ángel Redondo Medina y Emilio Gutiérrez Díaz (pocos meses después se incorporó Marcelino Pascual Torres), todos ellos miembros del Consejo de Administración. Registró la sociedad anónima el 1 de diciembre de 1916 ante el notario José María Aguirre y Serrat Calvó, e inscripta en el Registro Mercantil de la Provincia de Barcelona el 3 de enero de 1917, con duración indefinida ${ }^{13}$. El capital de la fábrica ascendió a 350.000 pesetas, y Carlos aportó personalmente los terrenos de Pueblo Nuevo así como también enseres, maquinarias y existencias de las maderas mencionadas, todo ello con el objetivo de continuar el negocio personal iniciado en 1908, y de vender los extractos y materias curtientes a toda Europa. El capital social fue representado por acciones al portador de 500 pesetas, cada una, de valor nominal. Las acciones se emitieron en dos series de títulos: una en 100 títulos de una acción cada uno, y otra en 120 títulos de cinco acciones cada uno. La sociedad anónima quedó regida por la Junta General de accionistas, con reuniones anuales convocadas con diez días de antelación en un periódico de la ciudad (en este caso, La Vanguardia), y con el derecho a un voto por cada diez acciones ordinarias: por ello, el accionista, poseedor de mayor número de acciones, dirigía la fábrica ${ }^{14}$.

Consumado el conflicto bélico internacional, el árbol de quebracho recuperó poco a poco su expansión comercial, y en el año 1922 el Puerto de Buenos Aires -es decir, el centro de captación de la producción argentina y paraguaya- facturó 129.000 toneladas de madera de quebracho. Fue en febrero de 1923 cuando se organizó una asamblea general celebrada por la Unión de Propietarios e Industriales del Pueblo Nuevo, en la cual se

\footnotetext{
${ }^{13}$ Se trata del folio 129 del tomo 97 del libro de Sociedades, número 10.451, inscripción primera.

14 Archivo del Registro Mercantil de Barcelona, Inscripciones de 1a - 22a, 58 folios, de 1916 a 1970, Folio 127, Hoja de Número 10.451, después número 50.531-NG, hoy folio número B-63.220, registros números A5418308 a A5418317, A5418406 a A5418416, A5418418 y A5418318 a A5418353, unida a certificación que forma parte, Inscripción del 3 de enero de 1917.
} 
acordó proyectar la instalación de una Central Eléctrica. Los elegidos fueron Juan Girona Vilanova, Ramón Castells Estrada, Manuel Saladrigas Freixas, así como el propio Carlos de Corral y Tomé. Para cumplir con los estatutos sociales, el Consejo de Administración de la “S. A. de Extractos Tánicos" empezó a convocar a sus accionistas a asambleas ordinarias y extraordinarias. De este modo, registraron dos años después unas 2.300 obligaciones de 500 pesetas cada una, equivalentes a 1.150 .000 pesetas $^{15}$. En 1927 acordaron aumentar el capital, así como la obligación de depositar diez o más acciones por accionista en un establecimiento bancario nacional o extranjero ${ }^{16}$. En noviembre del año siguiente declararon el aumento del capital social en otras 350.000 pesetas, representado por acciones al portador de 500 pesetas cada una, que gozaron de iguales derechos que las acciones en circulación. $^{17}$

Los efectos de este crecimiento pueden verificarse también en la organización del funcionamiento interno de la fábrica. Según nuestros datos, el plano general de la "S. A. de Extractos Tánicos" de Barcelona fue elaborado en marzo de 1923 a pedido de Carlos de Corral y Tomé. Dicho plano fue diseñado por Felipe Rajadel, y en él se observa la ubicación de la fábrica en la zona del ferrocarril del Pueblo Nuevo. La leyenda incluye también la ubicación del pasillo, escalera principal, portería, despacho, laboratorio, patio, depósito de mimosa, depósito de encina y de quebracho, batería, calderas, almacén, carga, depósito de bisulfito, almacén de carpintería, líneas de difusión, así como la sala de máquinas, almacenes, depósitos de extracto de mimosa, tenería experimental y los solares. Posteriormente, se levantó el plano de la fábrica de extractos tánicos, y se especificó la ubicación de la tenería experimental, las calderas de vapor, el laboratorio químico, la chimenea, el almacén, el despacho y la entrada a la empresa, los motores bomba, la sala de máquinas y el patio. Se dibujó el plan general de albañales para dejar salir las aguas sucias o residuales en el subsuelo de la fábrica. Se incluyeron las secciones de albañales de la sala de máquinas, la central y la de la tenería. La "S. A. de Extractos Tánicos” contó con un nuevo plano que muestra la instalación de los talleres y laboratorio, los almacenes, las calderas, las

15 Archivo del Registro Mercantil de Barcelona, Inscripciones de 1a - 22a, 58 folios, de 1916 a 1970, Folio 127, Hoja de Número 10.451, después número 50.531-NG, hoy folio número B-63.220, registros números A5418308 a A5418317, A5418406 a A5418416, A5418418 y A5418318 a A5418353, unida a certificación que forma parte, Carlos de Corral y Tomé, empleado, y Arnaldo Plà Serra, jornalero, 17 de setiembre del año 1925.

16 “Anuncios oficiales: S. A. de Extractos Tánicos, convocatoria", La Vanguardia, Barcelona, domingo 18 de febrero de 1923, p. 6; jueves 11 de junio de 1925, p. 6; viernes 23 de julio de 1926, p. 3; domingo 24 de julio de 1927, p. 4; martes 28 de julio de 1931, p. 3; miércoles 2 de agosto de 1933, p. 16.

17 Archivo del Registro Mercantil de Barcelona, Inscripciones de 1a-22a, 58 folios, de 1916 a 1970, Folio 127, Hoja de Número 10.451, después número 50.531-NG, hoy folio número B-63.220, registros números A5418308 a A5418317, A5418406 a A5418416, A5418418 y A5418318 a A5418353, unida a certificación que forma parte, Carlos de Corral y Tomé, empleado, y Arnaldo Pla Serra, del comercio, 9 de noviembre de 1928. 
máquinas, la oficina, la entrada, la portería, el laboratorio, los pasillos, grasos, el acceso al primer piso y al segundo piso, así como el sitio del molino.

La empresa que analizamos en este artículo conserva un folleto de la época referido a los "code condenser" internacionales, que sirvieron a la "S. A. Carlos Casado Limitada, Compañía de Tierras" para combinar un sistema de comunicación propio con la clave telegráfica particular de la "S. A. de Extractos Tánicos". En dicho folleto se incluyeron las instrucciones para cifrar los telegramas, así como las claves telegráficas. La palabra creada por el "código condensador" fue EDQOMBAGIR, que podía ser transformado en $\mathrm{ED} / \mathrm{QO} / \mathrm{MB} / \mathrm{AG} / \mathrm{IR}^{18}$. Es importante reproducir la publicidad de la "S. A. de Extractos Tánicos" que hizo la revista barcelonesa fundada por los de Corral y Tomé, primero llamada El Arte de Curtir, y posteriormente bautizada con el nombre de La Piely sus Industrias, el arte de curtir (Imagen 1).

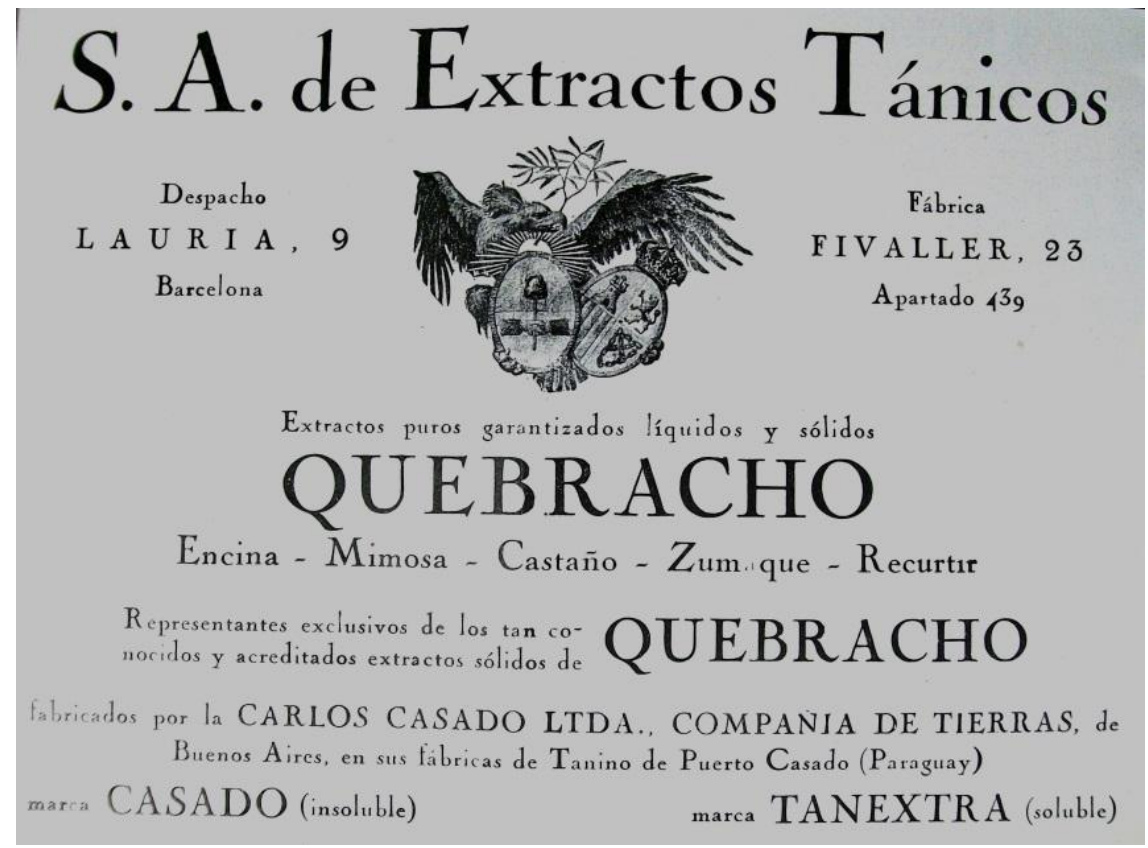

Imagen 1. Publicidad de la "S. A. de Extractos Tánicos".

Revista mensual La Piel y sus Industrias, el arte de curtir, Barcelona.

\footnotetext{
${ }^{18}$ Museo de Historia de Barcelona (MUHBA), Laboratorio, Code Condenser (Código Condensador), folleto elaborado por la "S. A. Carlos Casado Limitada, Compañía de Tierras", Buenos Aires, a la "S. A. de Extractos Tánicos”, Pueblo Nuevo de Barcelona, s/d (aprox. 1920).
} 


\section{LA EXPOSICIÓN INTERNACIONAL DE BARCELONA DE 1929}

En esos años la "S. A. de Extractos Tánicos" fue asegurada en Londres por la "Eagle, Star \& British Dominions Insurance Company Ltd.”, esta última fundada en el año 1807 en la Royal Exchange Avenue de Londres y dirigida por Sir Edward M. Mountain. A inicios de 1930 le tocó el turno al "Sun Insurance Office Limited", compañía inglesa de seguros contra incendios, que había sido fundada también en la capital británica en el año 1710, e inscripta en España el 8 de julio de 1909. En el primer caso, los de Corral y Tomé se inscribieron el 23 de febrero de 1922 con el objetivo de asegurar la importación de extractos sólidos del árbol leñoso mangle (en inglés, mongrove). La "S. A. de Extractos Tánicos" firmó también el documento de la "Royal Marine of Steamers of the Compañía Trasatlántica de Barcelona”, que le garantizó la importación de mangles desde Singapur gracias al agente "Barlow \& Co". En el caso de la compañía de seguros "Sun Insurance Office Limited", cuya agencia principal se encontraba en Bilbao, los de Corral inscribieron su nave de la calle de Perelló número 23 (antes Fivaller).

La transformación internacional de esta empresa catalana siguió el camino de la industrialización del curtido: la fábrica que analizamos aquí contaba con paredes de cerca y edificios, todos ellos de sólida construcción de piedra, cal y ladrillo, y cubiertos de tejas o terrado. Los pisos creados sobre la planta baja eran techos de bovedilla y ladrillo, cubiertos de tejas, con vigas de hierro y de madera, y con cobertizos cubiertos de uralita construidos en los patios. Por ello, "Sun Insurance” también aseguró las construcciones subterráneas, la maquinaria, las mercancías y los laboratorios de la "S. A. de Extractos Tánicos", que se movían con fuerza eléctrica y utilizaban la de vapor, esta última alumbrada por la electricidad.

En este periodo de entreguerras, el papel ejercido por la fábrica dedicada a los extractos tánicos fue reconocido internacionalmente: en febrero de 1929, por ejemplo, se produjo la reunión de la Unión Nacional de Fabricantes de Calzado en el Fomento del Trabajo Nacional de Barcelona ${ }^{19}$, con la intención de participar en la Exposición Internacional y de organizar en la ciudad condal el Congreso Nacional de Curtidores de España para constituir un comité gestor. Se trataba de una manifestación de vida industrial del curtido español, que esperaba aumentar el reconocimiento internacional a través de la

\footnotetext{
19 "Unión Nacional de Fabricantes de Calzado", La Piely sus Industrias, el arte de curtir, Año XX, n 243, febrero
} de 1929 , p. 3. 
Exposición Internacional de Barcelona ${ }^{20}$. Como afirmaron los responsables de la revista $L a$ Piel y sus Industrias, era el momento de luchar "con fe y sin tregua, contra los sucedáneos del cuero, llámense como se llamen, convencidos hoy más que nunca de que el cuero, el buen cuero, no tiene ni puede tener sustitutivo posible" 21.

Definida la Plaza España como un "lugar de maravilla"22, la inauguración de la Exposición Internacional dio paso a la valoración de su potencialidad económica: así lo afirmó la reciente revista técnica fiscal de carácter quincenal llamada Riqueza y Tributación, establecida por entonces en la Plaza Universidad número $1^{23}$. Para sus responsables ${ }^{24}$, la exposición demostraba el crecimiento del país y la realización de sus ideales en un porvenir no muy remoto ${ }^{25}$. Convencidos de que era imprescindible resguardar el comercio español ante los países europeos, también afirmaron que era inevitable el fomento de la fabricación de vestidos para el consumo femenino ${ }^{26}$.

Para ello, las relaciones con América Latina debían reforzarse a través de la importación de diversos productos, en particular del caucho, del petróleo, del cobre y del extracto tánico del árbol de quebracho colorado de la zona chaqueña del Cono Sur ${ }^{27}$. Fue entonces cuando la ya tradicional revista La Piel y sus Industrias transformó su organización: la administración se estableció con sus talleres tipográficos en la calle Aragón número 197, y se aumentó considerablemente la cantidad de colecciones gráficas de modelos inéditos. Fue esta revista barcelonesa creada por los hermanos de Corral y Tomé, la que, durante la inauguración de la Exposición Internacional de Barcelona de 1929, incluyó la portada titulada "arriba el telón":

Arriba el telón. Va a dar inicio el espectáculo...el escenario, vastísimo, comprende toda una ciudad. El argumento de la obra, es nada menos que el progreso intrínseco de una raza. Los espectadores que se disponen a ocupar asientos más o menos próximos al palco enemigo son jel mundo entero! Ante un momento tan sensacional como éste en que nos acecha el juicio crítico de cien naciones grandes

20 "El Congreso Nacional de Curtidores", La Piel y sus Industrias, el arte de curtir, Año XX, no 244, marzo de 1929 , p. 3.

21 "En el dintel de un nuevo año", La Piel y sus Industrias, el arte de curtir, Año XX, no 242, enero de 1929, p. 3.

22 [ARGOS]: "España ante el comercio mundial”, Riqueza y Tributación, Revista quincenal Técnica Fiscal, Año III, $\mathrm{n}^{\circ}$ 42, 20 de junio de 1929, pp. 658-659.

${ }^{23}$ CARBAJO ALFONSETTI, Eduardo: "Hacia adelante", Riqueza y Tributación, Revista quincenal Técnica Fiscal, Año III, no 42, 20 de junio de 1929, p. 656.

24 CAPMANY, Aureli: Barcelona aband de l'Exposició de 1888, Número Extraordinario dedicado a la Exposición Internacional de Barcelona, Barcelona, Librería Catalònia, Plaça Catalunya, 17, diciembre 1929, pp. 51-55.

${ }^{25}$ CARBAJO ALFONSETTI, Eduardo: "Pro consumo de artículos nacionales. Misión de la mujer española", Riqueza y Tributación, Revista quincenal Técnica Fiscal, Año III, no 48, 20 de septiembre de 1929, pp. 752-753.

26 CARBAJO ALFONSETTI, Eduardo: "En favor de la producción nacional: las modistas españolas", Riqueza y Tributación, Revista quincenal Técnica Fiscal, Año III, no 53, 5 de diciembre de 1929, pp. 832-833.

27 "El éxito de las Exposiciones", Riqueza y Tributación, Revista quincenal Técnica Fiscal, Año III, n 40, 20 de mayo de 1929, pp. 624-625. 
o pequeñas, no es desusado que contengamos la respiración.... ¡Así será! ¡Triunfará la Exposición Internacional de 1929 y con ella triunfan Barcelona y España! ¡Triunfará asimismo Sevilla, jardín de flores, herida de amor abierta en el corazón hispano, de cuyos caudales se ha nutrido un Nuevo Mundo. Triunfará el pueblo que trabaja, el pueblo que crea. ¡La visión augusta de las magnificencias del nordeste español y de una vez y para siempre la perniciosa leyenda de superficiales o indolentes que tanto daña a los buenos españoles! $!^{28}$.

Como sabemos, la Exposición Internacional de Barcelona contó con la presidencia de Alfonso XIII y del alto patronato del Ayuntamiento de Barcelona. La exposición gozó de tres grandes núcleos: el industrial, con los principales elementos de la producción; el llamado “arte en España” sobre arqueología y bellas artes; y el deportivo. En el primer caso figuraron once palacios que recibieron los productos de la industria y de la agricultura: fuerza motriz y maquinaria general; máquinas, herramientas; organización del trabajo, orientación profesional e higiene y seguridad del trabajo; agricultura y ganadería; minería; industrias textiles y del vestido; industrias de construcción, urbanismo y servicios municipales; artes industriales; artes gráficas; instrumentos de las ciencias y de las artes; comunicaciones y transportes; $y$, finalmente, las industrias químicas ${ }^{29}$.

El proyecto de los arquitectos Juan Roig y D. E. Canosa hizo posible levantar el Palacio del Vestido y del Arte Textil entre los palacios dedicados a Comunicaciones y Proyecciones, componiendo el fondo visible desde la Avenida de América. El palacio gozó de casi veinte mil metros cuadrados en la planta baja y alrededor de un hall central. Allí se exhibieron los recursos de las industrias textiles: en primer lugar, el material y los procedimientos de hilatura: material y procedimientos de los tejidos; blanqueo, tintes, estampados y aprestos; maquinaria; hilados y tejidos de algodón, lino y cáñamo; productos de cordelería; hilados y tejidos de lana y seda; géneros de punto; encajes, bordados y pasamanería; así como tejidos varios. En segundo lugar, el material y los procedimientos para la confección del vestido: máquinas de cortar las telas, pieles y cueros; maquinaria para hacer ojales; confecciones para hombres, mujeres y niños; industrias diversas del vestido; joyería y perfumería; sombrerería, camisería y lencería, corbatas, calzado; bastones, paraguas y sombrillas; botones de cerámica, metal, nácar, hueso, asta, papel; hebillas, ojetes y abanicos. En relación al curtido, y en base al principio de que "nada vale lo que el cuero",

28 “Arriba el telón”, La Piely sus Industrias, el arte de curtir, Año XX, no 245, abril de 1929, p. 6.

${ }^{29}$ Exposición Internacional, su significación y alcance, Barcelona, Seix y Barral Hermanos S. A., 1929, p. 11; pp. 1314. 
se impusieron los pabellones italiano ${ }^{30}$ y francés $^{31}$, dedicados ambos a los cueros (pieles), así como la magnífica "Shoe Machinery \& Company"

Los curtidores barceloneses, por su parte, se establecieron en el Palacio del Vestido para exponer las industrias de la piel, la marroquinería y el calzado. Encontramos a "Luis Ysamat", "C. Munmany", "Manuel Codina Planas", "Manufacturas Cuero Cosas, S. A.”, “José Funcá Monné”, "Bacás y Compañía de Badalona”, “José Carcasona”, "Drogas y primeras materias Paniker, S. A.”, "Alfonso Aliguer", "Manufacturas de la Piel, S. A.”, "Valentín Iglesias Abelló", así como la "Durall, Pujol y Cía.", y la de los hermanos de Corral y Tomé. Precisamente la “S. A. de Extractos Tánicos” fue valorada como la empresa más importante de la ciudad condal:

Sus amplias y confortables oficinas no se dan punto de reposo en cursar verdaderas lluvias de pedidos, que viniendo de todos los ámbitos de la península, ponen de manifiesto la estima en que la tenería española tiene a esta casa y extractos que fabrica, con los más modernos aparatos en sus grandes fábricas de Pueblo Nuevo. De abeja humana puede calificarse esta organización, y nada tiene de particular que así sea, hallándose al frente de la misma un trabajador infatigable como don Carlos de Corral y Tomé, excelente e ilustre amigo nuestro, cuya energía para el trabajo es inagotable y que en todo momento ha sabido y sabe excederse a sí mismo cuando se trata de demostrar que la raza latina no cede en ningún punto a la anglo-sajona en cuanto a empuje laborioso ${ }^{33}$.

Como afirmó la revista barcelonesa "La Piel y sus Industrias", la "S. A. de Extractos Tánicos" deleitaba al público por su unidad entre España y la Argentina (Imagen 2). Sus stands fueron los más celebrados durante el certamen organizado por sus miembros:

Fue su fundador don Pedro Pablo de Corral, hijo político del eximio ciudadano de origen español Carlos Casado del Alisal, el cual como saben nuestros lectores fue el alma animadora de la enorme manifestación de poderío industrial que consiguió transformar inmensas extensiones de selva virgen, allá en el Paraguay, en una red vastísima de establecimientos a la moderna que tienen su exponente ante el tráfico internacional en el admirable Puerto Casado. ${ }^{34}$

\footnotetext{
${ }^{30}$ Biblioteca Nacional de Catalunya (BNC), Exposición Internacional de Barcelona, Catálogo de la sección Italiana, Barcelona, 1929.

31 BNC, Exposition Internacionale de Barcelona, Sección Française, Classe des Cuirs et Peaux, Syndicat Général del Cuirs et peaux de France, Junta organizadora del Grupo de Curtidos a la Exposición Francesa en Barcelona, Cámaras Sindicales y Sindicatos Unidos, al "syndicat general de Cuirs et Peaux de France".

32 FORNS, J.: "El calzado en la Exposición Internacional de Barcelona”, La Piel y sus industrias, el arte de curtir, Año XX, agosto de 1929, nº 249, p. 23.

33 “S. A. de Extractos Tánicos", La Piel y sus Industrias, el arte de curtir, Año XX, no 253, diciembre de 1929, p. 23.

34 "S. A. de Extractos Tánicos", La Piel y sus Industrias, el arte de curtir, Año XX, n 253, diciembre de 1929, p. 23.
} 


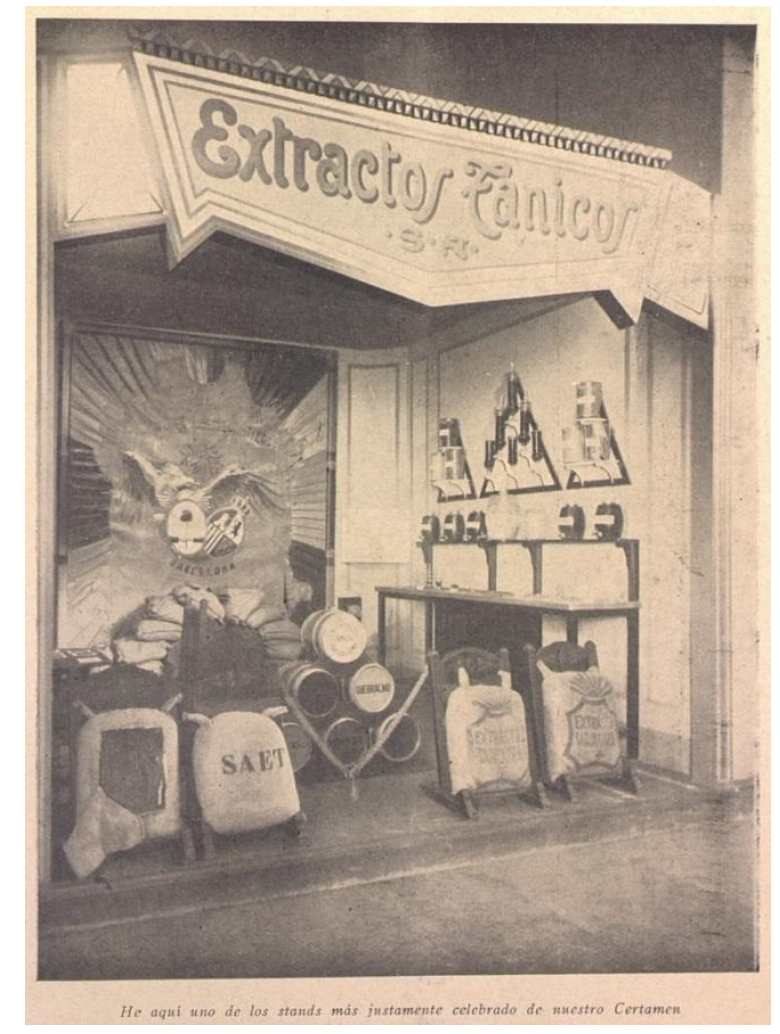

Imagen 2. La "S. A. de Extractos Tánicos" durante la Exposición Industrial de Barcelona de 1929. Revista mensual La Piely sus industrias, Barcelona. Año XX, n 253, diciembre de 1929, p. 23.

Por entonces, la "S. A. de Extractos Tánicos" era más que conocida, y, para la revista barcelonesa, "citar los extractos de esta casa, es lo mismo que decir, eficacia, perfección y acierto". Por ello La Piel y sus Industrias le dedicó un extenso reconocimiento a la fábrica y, en especial, a Carlos de Corral y Tomé, acompañado del secretario del Consejo de Administración, Arnaldo Pla Serra, y del vocal Emilio Guillén Gutiérrez:

Nosotros que en diversas ocasiones nos hemos encontrado con Don Carlos de Corral en el Extranjero, sabemos hasta qué punto es cierto lo que decimos, pues hemos podido ser testigos de su voluntad de hierro para el trabajo, que le hace robar horas al descanso recorriendo desde primeras horas de la mañana los centros industriales que le interesa conocer, y encerrándose en su habitación del hotel, hasta altas horas de la madrugada, estudiando muestras, cotejando cifras y extrayendo el máximo provecho de lo que ha visto. Enemigo de perder el tiempo, hombre serio y estudioso hasta la exageración, nos hace declarar sinceramente que si existiesen muchos hombres como él en España, desaparecería para siempre la fama de distraídos y superficiales, de que injustamente gozamos en el extranjero....Cerramos esta información testimoniando una vez más a don Carlos de Corral y Tomé la sincera efusión de nuestro afecto y la profunda admiración que sentirnos ante sus éxitos comerciales, de los cuales nos vanagloriarnos como cosa propia ${ }^{35}$.

35 "S. A. de Extractos Tánicos", en: La Piel y sus Industrias, el arte de curtir, Año XX, n 253, diciembre de 1929 , p. 23. 
Ahora bien: junto a los empresarios participaron la Unión Nacional de Fabricantes de Calzado, el Sindicato General de Fabricantes de Curtidos, la Cámara Sindical de la Marroquinería, la Agrupación de Confeccionistas Camiseros y Corbateros al por mayor de Barcelona, la Asociación de Fabricantes de Tirantes y Ligas, así como las Industrias del Vestido ${ }^{36}$. De acuerdo al Reglamento General de la Exposición Internacional de Barcelona de 1929, y al de la Convención de París del 22 de noviembre de 1928, se creó un Jurado Internacional encargado de otorgar recompensas: La Piel y sus Industrias recibió un gran premio de medalla de oro, así como el diploma de honor en el V Congreso Internacional de la Prensa Técnica y Profesional ${ }^{37}$.

Por ello, Juan Forns Moral defendió la presencia de estas entidades así como la de las propias industrias de la piel $^{38}$, pero reconoció la ausencia de un buen número de empresarios en el marco de la Exposición Internacional barcelonesa en virtud de una más que posible crisis económica internacional:

La crisis que atraviesan la piel y los calzados han influido en la deserción de quienes no debían faltar. No acuso, lamento. En cambio, aplaudo con toda sinceridad a los que, a pesar de la crisis, han lanzado sus muestras a la Exposición, en espera de mejores resultados que los pesimistas. Ojalá su esfuerzo se vea compensado y para que así sea tengo una pluma y un pensamiento que aunque muy modestos se ofrecen respetuosamente para todo lo que signifique romper una lanza pro Industria Nacional ${ }^{39}$.

Estaba todavía en discusión el futuro de la producción industrial de curtidos ${ }^{40}$. Según la revista La Piel y sus Industrias:

En buena lógica no puede desearse que el consumo disminuya....debemos reconocer que la industria de curtidos está dando sus primeros pasos en la consecución de una prosperidad estable...esta campaña podría reposar sobre tres puntos fundamentales adecuados todos a incrementar la colocación de nuestros productos y son: guerra sin cuartel a los sucedáneos, hasta evidenciar la incontestable superioridad del cuero auténtico; mejoramiento pertinaz e incansable de los procedimientos de curtición y acabado, hasta conseguir eliminar por medios lícitos la concurrencia extranjera; propagar y difundir cada día cada

\footnotetext{
36 Biblioteca Nacional de Catalunya (BCN), Exposición Internacional de Barcelona, Guía del Visitante, Barcelona, Palacio del Vestido (folleto), 1929.

37 Biblioteca Nacional de Catalunya (BCN), Exposición Internacional de Barcelona: Jurado Internacional de Recompensas: reglamento, Anuarios Bailly-Baillière y Riera Reunidos, Barcelona, Impreso en los Talleres Gráficos de Andrés Mir, 1929.

38 "Nuestras mejoras", La Piely sus Industrias, el arte de curtir, Año XXI, n² 254, enero de 1930, p. 6.

${ }^{39}$ FORNS, J., "Las Industrias de la Piel en la Exposición de Barcelona", La Piel y sus Industrias, el arte de curtir, Publicación mensual ilustrada, adherida a la Asociación Española de la Prensa Técnica, de gran circulación en España y América Latina, Barcelona, Año XX, no 248, julio de 1929, p. 23.

${ }^{40}$ La Piely sus Industrias, el arte de curtir, Año XXI, no 257, abril de 1930, p. 6.
} 
hora y cada minuto las excelencias del cuero, como artículo de primera necesidad, afirmando y vigorizando sus muchas aplicaciones actuales, y descubriéndole otras nuevas, que puedan constituir, como las conocidas, fuentes de riqueza ${ }^{41}$.

En virtud del interés productivo volcado al curtido de la suela ${ }^{42}$, durante la Exposición Internacional de Barcelona se organizó un pabellón único ${ }^{43}$, el cual unificó las Juntas Directivas de todos los organismos en que se hallaban agrupados los fabricantes ${ }^{44}$, en particular los de calzado, curtidos, marroquinería, guantes, tacones, hormas, ojetes, tintes, suelas, artículos de viaje, extractos curtientes, accesorios, marroquinería... ${ }^{45} \mathrm{Su}$ finalidad era unificar el "Ramo de la Piel" ". Pero pese a esta intensa organización, la ausencia de empresas volcadas a la publicidad condicionó el futuro de la revista y de las fábricas que se publicitaban en sus páginas: es visible el creciente número de páginas en blanco de la sección publicitaria de la revista La Piely sus Industrias.

Quizás por ello, y al imitar el "castillo de fuego" representado por la Exposición Internacional $^{47}$, los empresarios catalanes decidieron copiar el modelo implementado en Francia en 1927, y proyectaron la organización de la "Semana del Cuero de España"48. Ante ello, los responsables de la publicación barcelonesa se unieron a los de la revista madrileña Gaceta de Cueros y Calzado, y afirmaron:

Es nuestra hora. Largo tiempo llevamos batallando en pro de una idea que estimamos salvadora y utilísima...se asemeja a esas lucecitas de los faros que aparecen cada día a la misma hora y sirven para orientar a los navegantes y guiarles a través de los escollos...Sería lamentable y bochornoso, como opina muy bien nuestro querido colega Gaceta de Cueros y Calzado que la Semana del Cuero de España quedase reducida a un jalón más en la escala de los buenos propósitos incumplidos...curtidores, almacenistas, fabricantes de calzado, de extractos, de accesorios, marroquineros, guarnicioneros, paleteros, guanteros, etc., juntan vuestra voz a la nuestra y exhalemos un estentóreo viva a la Semana del Cuero de España $^{49}$.

\footnotetext{
41 "Las Industrias de la Piel en la Exposición Internacional de Barcelona", La Piely sus Industrias, el arte de curtir, Año XX, no 246, mayo de 1929, p. 6.

42 "La suela curtida al cromo", La Piel y sus Industrias, el arte de curtir, Año XIX, no 238, setiembre de 1928, p. 134.

43 “El pabellón único", La Piel y sus Industrias, el arte de curtir, Año XIX, no 239, octubre de 1928, p. 150.

${ }^{44}$ La Piely sus Industrias, el arte de curtir, Año XX, no 249, agosto de 1929.

${ }^{45}$ La Piel y sus Industrias, el arte de curtir, Año XX, no 250, setiembre de 1929

46 "Hacia un Congreso de las Industrias de la Piel en España", La Piel y sus Industrias, el arte de curtir, Año XX, $\mathrm{n}^{\mathrm{o}} 252$, noviembre de 1929 , p. 5.

47 "Propio y ajeno", La Piely sus Industrias, el arte de curtir, Año XX, nº 247, junio de 1929, p. 6.

48 "Miremos hacia adelante", La Piely sus Industrias, el arte de curtir, Año XX, n 248, julio de 1929, p. 6.

49 "La semana del cuero de España", La Piel y sus Industrias, el arte de curtir, Año XXI, no 257, abril de 1930, p. 6.
} 
Pese a estos importantes proyectos que se describieron insistentemente en La Piel y sus Industrias, el futuro no estaba para nada garantizado. Por ello es importante mencionar a los representantes-delegados y a los viajantes de la "S. A. de Extractos Tánicos" en España y Portugal. De acuerdo al registro de las comisiones recibidas en el año 1932, desde esa fecha aquellos delegados y viajantes perdieron la posibilidad de continuar su contacto con esta importante empresa barcelonesa vinculada al Paraguay ${ }^{50}$.

\begin{tabular}{|l|l|l|l|}
\hline $\begin{array}{l}\text { Representante de la "S. A. } \\
\text { de Extractos Tánicos" }\end{array}$ & Localidad actuación & $\begin{array}{l}\text { Representante de la "S. A. } \\
\text { de Extractos Tánicos" }\end{array}$ & Localidad actuación \\
\hline Altamiro \& Filhos & Oporto & Miranda, Aurelio & Santander \\
\hline Azcárate, Vicente & Vergara & Moreno Moya, Eusebio & Madrid \\
\hline Botella, Desiderio & Alcoy & Otero Seijas, Genaro & Pontevedra \\
\hline Campuzano, Juan & Málaga & Portilla, Francisco & La Bañeza \\
\hline Eléxpuru Santiago, J. & Vigo & Quiles Prósper, José & Gandia \\
\hline $\begin{array}{l}\text { Viuda de) Eléxpuru Santiago, } \\
\text { J. }\end{array}$ & Vigo & Riera Cañedo, Manuel & Cádiz \\
\hline Fábregas Costa, Jaime & (viajante) & Romani Riva, Rodrigo & Noya \\
\hline Farexco, V. L. (S. R.) & Vigo & Roselló, Francisco & Palma de Mallorca \\
\hline Frapo Martí, Antonio & (viajante) & Sabate, Emilio & Igualada \\
\hline Gaza, Pedro A. & Palma de Mallorca & Santos, ¿Luis? & Pamplona \\
\hline Hernández Echart, Juan & San Sebastián & Santos, Ricardo & Pamplona \\
\hline Jofre Espinosa, Serafín & (viajante) & Solache Blanco, Fernando & Villarramiel \\
\hline Lizarán Valera, Francisco & Lorca & Tafalla, Jesús & Zaragoza \\
\hline Lora Hidalgo, Mariano & Salamanca & Tost Pavia, Miguel & Sabadell \\
\hline Llobregat, Isidoro & Valencia & Vidal Mengual, Antonio & (viante) \\
\hline
\end{tabular}

Ahora bien, también interesa señalar que la empresa contrató el 24 de febrero de 1934 la póliza número 16.172.320 de "Sun Insurance", y poco después, el 20 de febrero de 1936, sumó otra póliza del seguro (número 17.036.535) que se fijó en 900.000 pesetas con una vigencia de diez años. Esta suma asegurada fue repartidas entre las edificaciones (280.000 pesetas); la maquinaria, la montacargas, los útiles y los recambios (320.000 pesetas); materias para la industria, en especial las "cortezas, maderas y raíces europeas, con exclusión de las exóticas como tizra y quebracho, y productos de la misma, en cualquier estado de fabricación o terminados y dispuestos para la venta, y sobre todo los envases para dichas materias y productos" (200.000 pesetas); los pisos sin comunicación con los edificios

50 MUHBA, Laboratorio, Libro de Comisiones de representantes de la "S. A. de Extractos Tánicos", Barcelona, 1932. 
vecinos, de los que estaban separado por paredes de $30 \mathrm{~cm}$ (40.000 pesetas); la instalación de máquinas en el taller de reparaciones, en especial bancos, tornos y herramientas (16.000 pesetas); el cobertizo de uralita, el cortador y la instalación del molino (40.000 pesetas); y, finalmente, el seguro por el pago del arbitrio municipal y la asistencia del material y del personal ante casos de incendio (16.000 pesetas). Los seguros de la "S. A. de Extractos Tánicos" coincidieron con el crecimiento indudable de la importación del quebracho ${ }^{51}$, pero desaparecieron desde el momento en que se desató la Guerra Civil española.

El 18 de febrero de 1937, en plena Guerra Civil, la “S. A. de Extractos Tánicos” declaró a la compañía aseguradora "Sun Insurance" que su chimenea se había caído por los rayos, y que "en la actualidad tiene la fábrica totalmente paralizada, dedicándose solamente al almacenaje de las mercancías de su industria”. La Agencia de Barcelona, establecida en el principal de la calle Pelayo número 58, se encontraba por entonces dirigida por el Comité de Control Obrero de la Unión General de Trabajadores (UGT), pero prometió continuar con la póliza del servicio de incendios. En plena Guerra Civil española, la "S. A. de Extractos Tánicos" fue colectivizada y paralizada a efectos de producción.

Como vemos, la empresa gestada por los hermanos de Corral y Tomé en Barcelona -gracias a la unión familiar con los Casado-Sastre establecidos en Argentina y Paraguay- ${ }_{-}^{52}$, sufrió una gran decadencia económica de la que sólo se recuperó de la mano de la familia catalana Durall-Pujol. En efecto, desde el año 1940 se hicieron cargo de la fábrica dedicada al extracto tánico para el curtido. La exportación-importación de rollizos de madera de quebracho, que era la base por la que se constituyó la "S. A. de Extractos Tánicos”, siguió el camino europeo al perder interés ante el quebracho colorado producido en la zona chaqueña paraguaya ${ }^{53}$.

\section{REFLEXIONES FINALES}

Durante la Exposición Industrial de Barcelona del año 1929 se produjo la terrible crisis económica de Wall Street, la cual transformó el sentido de la "S. A. de Extractos Tánicos". La empresa sufrió una gran declinación productiva ante el fallecimiento de Carlos de Corral y Tomé en el año 1934, y que se agravó en el contexto de la Guerra del Chaco (1932-1935),

\footnotetext{
51 DALLA-CORTE CABALLERO, Gabriela: Empresas y tierras de Carlos Casado en el Chaco Paraguayo. Historias, negocios y guerras (1860-1940), Asunción del Paraguay, Intercontinental Editora, 2012.

52 Registro Mercantil y de Bienes Muebles de Barcelona, volumen 881, libro 402, folio 67, hoja 4281, inscripción 1; últimas, volumen 4333, folio 82, hoja B 38892, inscripción 20. Inscripciones 1 a 20, Registro números A5373287 al AA5373312, A5372542, A5372543, A5373434, y de A5372545 a A5372568, datos del 11 abril de 2013.

${ }^{53}$ RÍO, Carlos Ramiro del: El extracto de quebracho: origen y evolución, Buenos Aires, Editorial Dunken, 2004.
} 
de la Guerra Civil española (1936-1939) y de la Segunda Guerra Mundial (1939-1945). La lucha entre el caucho y el quebracho fue parte de este gran conflicto internacional que se sumó de manera indirecta a la Guerra Civil española, y que transformó a la fábrica de extractos curtientes barcelonesa destinada a la producción de curtidos. Durante las guerras mencionadas, la fábrica dejó de recibir los rollizos, es decir, los recursos naturales imprescindibles para la producción del calzado y de las botas de los ejércitos europeos en manos de las industrias catalanas.

Desde mediados del siglo XX el regaliz se convirtió en un producto de exportación: entre 1945 y 1950 España exportó 694 toneladas de raíz de regaliz, así como 2.029 toneladas de extracto de regaliz. Los países receptores más importantes fueron Argentina, Australia, Brasil, Dinamarca, Estados Unidos, Finlandia, Gran Bretaña, Noruega, Suiza y, en especial, los Estados Unidos, que eran el principal cliente de la producción española de raíz de regaliz (orozuz) y de extracto de regaliz para aromatizar el tabaco de la famosa industria “Tabacalera S. A.”. En 1952 España produjo 12.000 toneladas de raíz de regaliz, la planta leguminosa de flores azuladas que crecían al costado de los ríos (paloduz), y que adoptó las formas de bloques, panes, barritas y pastillas. Como afirmó Francisco Torregrosa Lastres, por entonces secretario de los Servicios de Exportación de la Dirección General de Comercio, se trataba de un vegetal conocido desde la antigüedad, proveniente del Oriente Medio y de los países limítrofes del Mediterráneo, que contenía sustancias dulces como el azúcar y la glicirrima ${ }^{54}$.

Ubaldo Cuffi Roura, el jefe de los Laboratorios de Investigaciones y Análisis del “C.I.T.A., S. A.”, utilizó las páginas de la revista Circular Farmacéutica de la Vía Layetana número 94 de Barcelona, y afirmó que el material se debía escoger en función de su composición. Por ello describió el proceso de fabricación del extracto blanco de regaliz que por entonces tuvo nuevas posibilidades de aplicación ya que reunía los requisitos exigidos por la farmacopea, y que se usaba en la práctica farmacéutica e industrial ${ }^{55}$. El extracto blando incluyó los aparatos necesarios para producir el regaliz a través de los rizomas y raíces desecadas de la "glycirrhiza galbra L.", la planta perteneciente a la familia de las leguminosas abundantes de España, en especial cerca de los ríos ${ }^{56}$.

\footnotetext{
54 TORREGROSA, F., "Los Colorantes y sus problemas", Información comercial española, $3^{\circ}$ época, marzo, $\mathrm{n}^{\circ}$ 223 (1952), pp. 326-335.

55 CUFFI ROURA, Ubaldo: "La fabricación del extracto de regaliz", Circular Farmacéutica, Cientifica y Económica, 131-133 (1954), pp. 228-232.

${ }^{56}$ CUFFI ROURA, Ubaldo: “Aspectos científicos a considerar en el empaquetado de sustancias sólidas, granuladas o en polvo”, Circular Farmacéutica, Científica y Económica, 181 (1959), pp. 11-15.
} 
Por entonces, el regaliz se empleaba también en medicina y servía para la fabricación del papel del regaliz que se usaba como indicador en las refinerías de petróleo ${ }^{57}$. Por ello, la industrialización del regaliz ya daba un lugar al extracto que constituía la principal exportación española. Esta es la historia de esta empresa barcelonesa vinculada estrechamente al Chaco Paraguayo hasta mediados del siglo XX. En la década de 1960, la antigua fábrica del Pueblo Nuevo optó por incorporar el extracto del regaliz ("glucyrrhiza glabra") ${ }^{58}$, muy utilizado a nivel sanitario ${ }^{59}$. El regaliz sustituyó completamente al extracto tánico del quebracho en el Pueblo Nuevo barcelonés ${ }^{60}$.

En síntesis, las añejas estructuras catalanas que durante tantas décadas habían sido inamovibles, presentaron a inicios del siglo XX unas anheladas perspectivas de cambio que no podían desaprovecharse: la creación de pequeñas y medianas fábricas, algunas de las cuales todavía tienen vigencia en Cataluña, fue el fruto de dichas perspectivas que constituyen una importante base sobre la que se sustenta buena parte de la sociedad. Las pequeñas y medianas empresas representaron el cambio de rumbo y acompañaron el aumento de la importación de pieles en bruto y de extractos vegetales para la curtición. Los rollizos de madera del quebracho, que era la base por la que se constituyó la "S. A. de Extractos Tánicos", dejaron de importarse en el Pueblo Nuevo barcelonés. En consecuencia, el Puerto barcelonés dejó de recibir el tanino del Chaco Paraguayo en el marco de la transformación de la economía internacional. Se difuminó así el interés por el quebracho colorado producido en la zona chaqueña paraguaya, ya que el futuro del curtido catalán estaba en manos del tanino sintético, mientras la empresa analizada en este artículo se volcó directamente a la producción del extracto tánico del regaliz.

\footnotetext{
${ }^{57}$ TORREGROSA, F., "El Regaliz en la estructura económica de España", Información comercial española, $3^{\circ}$ época, abril, $\mathrm{N}^{\circ} 224$ (1952), pp. 520-523.

58 SERRANO GARCÍA, Manuel: "Contribución al estudio del regaliz español”, Farmacognosia, Anales del Instituto José Celestino Mutis, vol. 5, no 9 (1946), pp. 9-74.

${ }^{99}$ FERNÁNDEZ IBÁÑEZ, A.: "Tratamiento de la úlcera gastro-duodenal (U.G.D.), con un compuesto de extracto de regaliz" (jefe del Servicio de Aparato Digestivo del S. O. de E. Sanatorio José Antonio Girón, Valladolid), Revista clinica española, LVIII/2 (31 de julio, 1955), pp. 96-100.

60 "S. A. de Extractos Tánicos", La Vanguardia, Barcelona, martes 28 de abril de 1981, p. 67; miércoles 16 de setiembre de 1981, p. 40.
} 